\title{
A Proposed CT Classification of Progressive Lung Parenchymal Injury Complicating Paediatric Lymphobronchial Tuberculosis - from reversible to irreversible lung injury
}

\author{
Savvas Andronikou ${ }^{1}$, Susan Lucas ${ }^{2}$, Andrea Zouvani ${ }^{3}$, and Pierre Goussard ${ }^{4}$ \\ ${ }^{1}$ The Children's Hospital of Philadelphia \\ ${ }^{2}$ University of the Witwatersrand \\ ${ }^{3}$ University of Glasgow \\ ${ }^{4}$ Stellenbosch University
}

November 23, 2020

\begin{abstract}
Abstract Lymphobronchial tuberculosis (LBTB) is tuberculous lymphadenopathy affecting the airways, which is particularly common in children with primary TB. Airway compression by lymphadenopathy causes downstream parenchymal pathology, which may ultimately result in irreversible lung destruction, if not treated timeously. CT is considered the "gold standard" for detecting mediastinal lymph nodes in children with TB. CT is also the best way of imaging the airways of children with LBTB. The CT findings of the parenchymal complications and associations of LBTB on CT have been described, but no severity classification was provided to aid management decisions. Identifying the parenchymal complications of LBTB and recognising their severity has clinical relevance. Using prior publications on LBTB and post obstructive lung injury we have used an image bank of CT scans in children with pulmonary TB, presenting with airway symptoms, to create a CT severity staging of lung injury in LBTB. The staging focuses on distinguishing non-salvageable destruction [non-enhancing or cavitated lung] from salvageable lung parenchymal disease [enhancing and non-cavitated] to inform the management decisions, which range from bronchoscopic airway clearance to surgical decompression of the compressing nodes.
\end{abstract}

\section{Hosted file}

V2 Proposed CT classification of lung injury in lymphobronchial TB.pdf available at https: //authorea.com/users/378131/articles/494688-a-proposed-ct-classification-of-progressivelung-parenchymal-injury-complicating-paediatric-lymphobronchial-tuberculosis-fromreversible-to-irreversible-lung-injury 


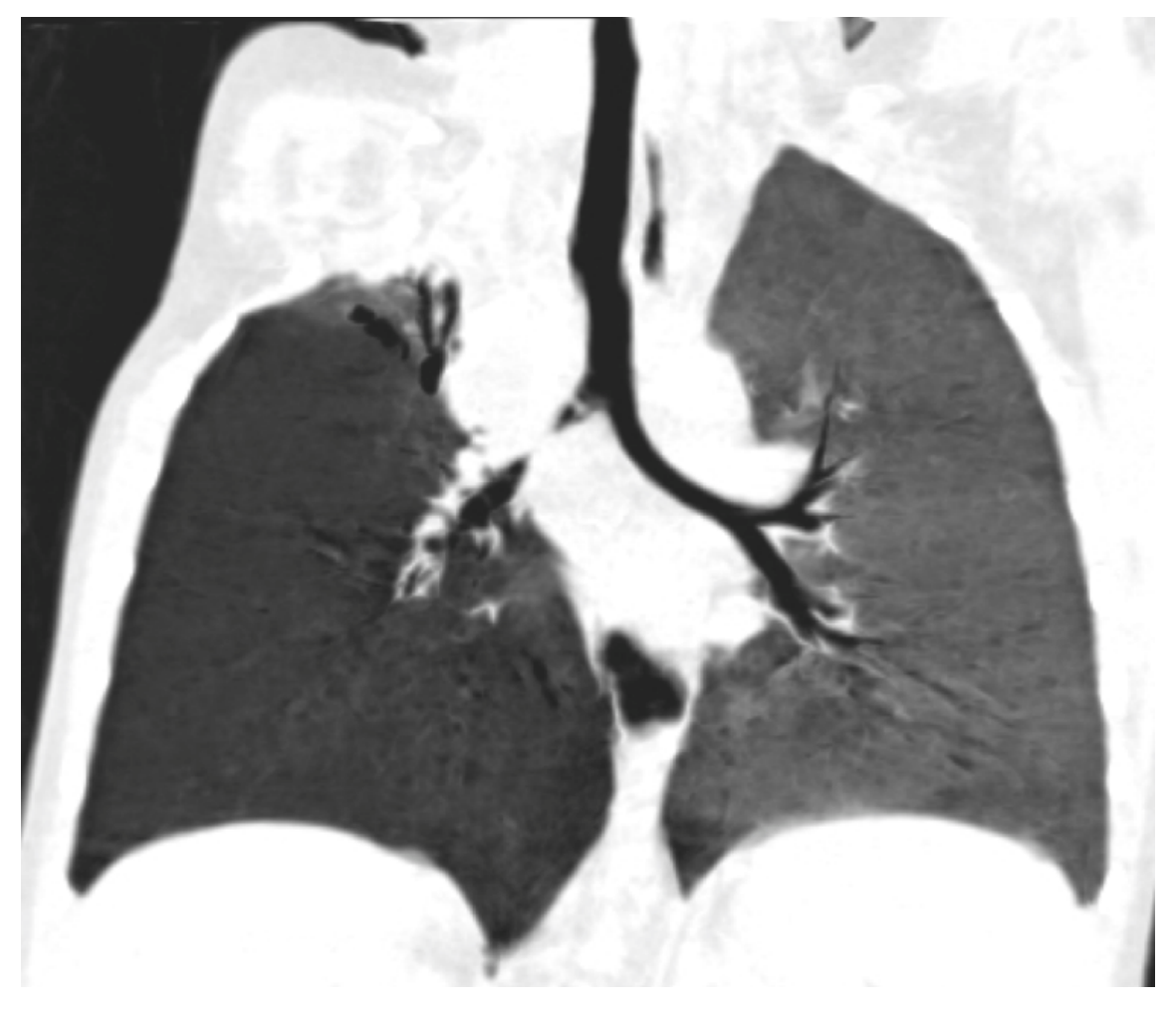




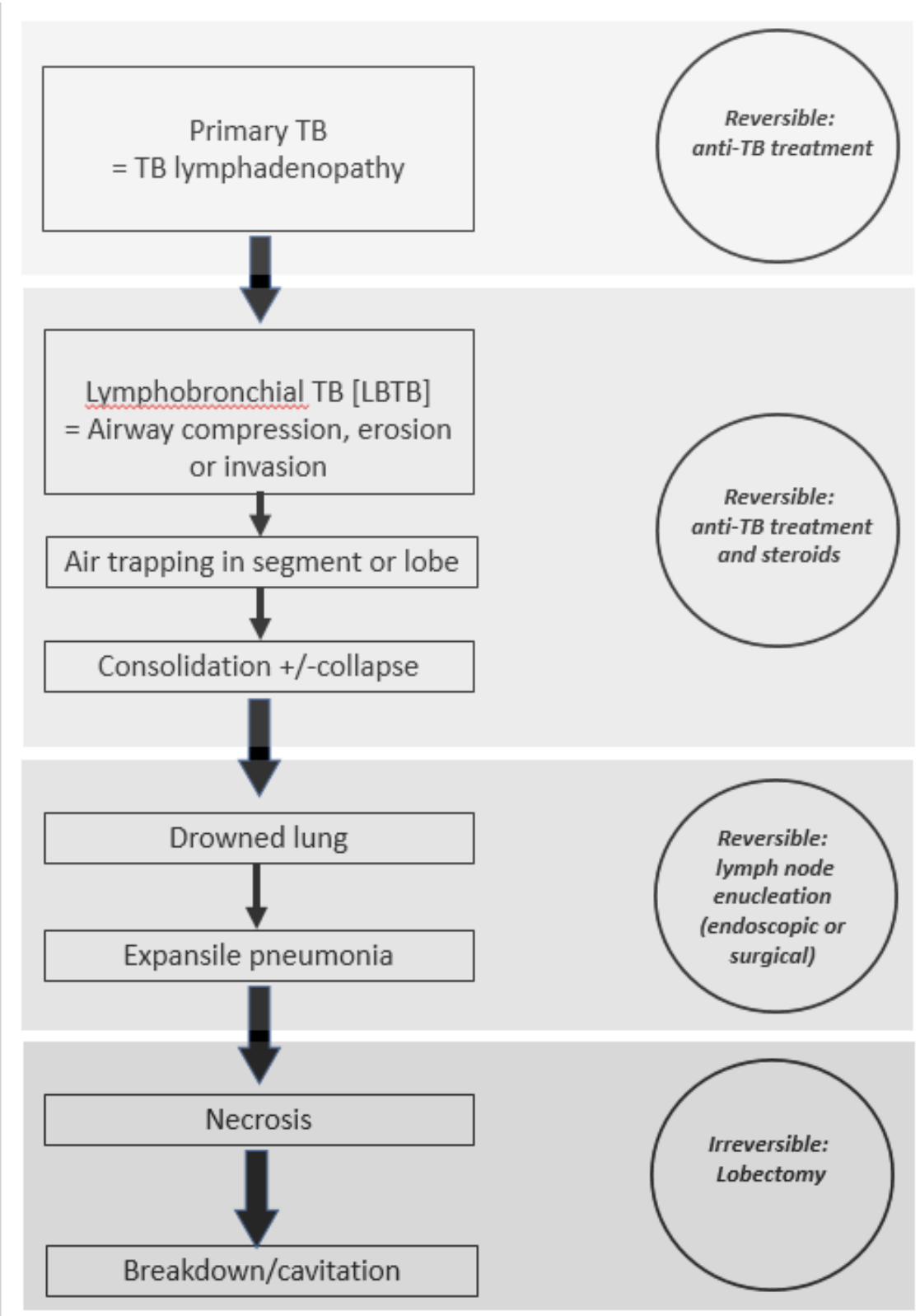




\begin{tabular}{|c|c|c|c|c|c|c|}
\hline \multicolumn{7}{|c|}{ CT Severity classification of parenchymal complications in Lymphobronchial TB } \\
\hline Stage & Parenchyma & Density & Volume & Contrast & Other & CT scanning \\
\hline 0 & Normal & $\begin{array}{l}\text { Air - } \\
\text { Normal }\end{array}$ & Normal & $\mathrm{n} / \mathrm{a}$ & $\begin{array}{l}\text { Hilar / sub-carinal } \\
\text { Lymphadenopathy } \\
\text { causing airway } \\
\text { compression (arrows) }\end{array}$ & \\
\hline 1 & Air trapping & $\begin{array}{l}\text { Air - } \\
\text { decreased }\end{array}$ & Increased & $n / a$ & Hyperinflation & \\
\hline$\|$ & $\begin{array}{l}\text { Consolidation } \\
\text { +/- collapse }\end{array}$ & $\begin{array}{l}\text { Soft tissue } \\
\text { density }\end{array}$ & $\begin{array}{l}\text { Normal*/ } \\
\text { decreased }\end{array}$ & Enhancing & $\begin{array}{l}\text { +/-Air-bronchograms } \\
\text { Displacement towards } \\
\text { collapse }\end{array}$ & \\
\hline III & $\begin{array}{l}\text { Drowned } \\
\text { lung }\end{array}$ & $\begin{array}{l}\text { Soft tissue } \\
\text { density = } \\
\text { fluid-filled } \\
\text { bronchi }\end{array}$ & * & Enhancing & Fluid-bronchograms & \\
\hline IV & Necrosis & $\begin{array}{l}\text { Fluid } \\
\text { density }\end{array}$ & * & Non-enhancing & & \\
\hline $\mathrm{v}$ & Cavitation & Air & Variable & Non-enhancing & $\begin{array}{l}\text { Irregular air-filled } \\
\text { cavities (arrows) }\end{array}$ & \\
\hline $\begin{array}{l}{ }^{*} \text { If any } \\
\text { be term }\end{array}$ & $\begin{array}{l}\text { f groups III, IV ar } \\
\text { d AN expansile }\end{array}$ & $\begin{array}{l}\mathrm{d} V \text { demonst } \\
\text { oneumonia }\end{array}$ & rate a bulging & ssure (arrow) an & creased volume, it would & \\
\hline
\end{tabular}

